\title{
Co-expression in Helicobacter pylori of cagA and non-opsonic neutrophil activation enhances the association with peptic ulcer disease
}

\author{
D Danielsson, S M Farmery, B Blomberg, S Perry, H Rautelin, J E Crabtree
}

Department of Clinical Microbiology and Immunology, Örebro Medical Centre Hospital, Örebro, Sweden

D Danielsson

Division of Gastroenterology, Department of Internal Medicine, Örebro Medical Centre Hospital B Blomberg

Molecular Medicine Unit, Level 7 Clinical Sciences Building, St James's University Hospital, Leeds LS9 7TF, UK

S M Farmery

S Perry

J E Crabtree

Department of

Bacteriology and Immunology,

University of Helsinki, Helsinki, Finland

H Rautelin

Correspondence to: Dr Crabtree email:

MSJJC@stjames.leeds.ac.uk

Accepted for publication 10 November 1999

\begin{abstract}
Aims-To investigate the association of cagA positivity and non-opsonic neutrophil activation capacity in wild-type Helicobacter pylori strains with peptic ulcer disease or chronic gastritis only. Methods-Helicobacter pylori were isolated from antral biopsies of 53 consecutive patients with chronic antral gastritis, of whom 24 had peptic ulcer disease endoscopically. The presence of cagA, a marker for the cag pathogenicity island, was determined by polymerase chain reaction with specific oligonucleotide primers, and non-opsonic neutrophil activation capacity by luminol enhanced chemiluminescence.

Results-The cagA gene was present in 39 of $53(73.6 \%)$ strains, 20 of which $(83.3 \%)$ were from the 24 patients with peptic ulcer disease and $19(65.5 \%)$ from the 29 patients with chronic gastritis only. Nonopsonic neutrophil activation was found in $29(54.7 \%)$ strains, 16 of which $(66.7 \%)$ were from patients with peptic ulcer disease, and $13(44.8 \%)$ from those with chronic gastritis. Non-opsonic neutrophil activation was found more frequently in cagA $^{+}$than cagA $\mathrm{A}^{-}$strains (59\% $\left.v \quad 42.9 \%\right)$. Whereas four of the $14 \mathrm{cagA}^{-}$strains and eight of the 24 non-opsonic neutrophil activation negative strains were from patients with peptic ulcer disease, only two of $24(8.3 \%)$ peptic ulcer disease strains expressed neither cagA nor nonopsonic neutrophil activation. The $\operatorname{cag} A$ gene and non-opsonic neutrophil activation capacity were co-expressed in 14 of 24 $(58.3 \%)$ strains from patients with peptic ulcer disease, and in nine of $29(31 \%)$ strains from individuals with chronic gastritis.

Conclusions-Positivity for cagA and non-opsonic neutrophil activation occur independently in wild-type $H$ pylori strains. However, co-expression of the two markers enhanced the prediction of peptic ulcer disease.

(f Clin Pathol 2000;53:318-321)
\end{abstract}

Keywords: Helicobacter pylori; neutrophil; cagA

There is convincing evidence that Helicobacter pylori infection is the main cause of peptic ulcer disease and a very important cofactor for the development of gastric cancer. ${ }^{1-3}$ It is also one of the world's most common bacterial infec- tions. However, only a small number of infected individuals will suffer from clinically overt gastroduodenal disease and the reasons for this are unclear. The production of large amounts of urease and the presence of flagella (four or five) for swimming through the mucous layer ${ }^{4}$ are seen in all clinical isolates, and are necessary for the colonisation of the stomach and survival in this hostile environment. In addition to these putative factors, which might explain why all infected persons develop chronic superficial gastritis with accumulation of lymphocytes, macrophages, and plasma cells, there is increasing evidence that some strains are more virulent than others.

The extent of the chronic gastritis is determined by the infiltration of neutrophils in the gastric mucosa and epithelial layer, which might be important factors for tissue damage and ulceration. ${ }^{6}$ CagA is a phenotypic marker for proinflammatory $H$ pylori strains that induce production of interleukin 8 (IL-8) in gastric epithelial cells. ${ }^{78}$ Secreted IL-8 will bind to proteoglycans within the matrix of lamina propria and, together with $H$ pylori, will attract neutrophils and facilitate their migration towards the epithelium. ${ }^{9}$ In the search for virulence factors to predict clinical outcome, many studies have demonstrated the presence of cagA, a marker for the cag pathogenicity island, ${ }^{1011}$ and particular alleles of the vacA gene to be associated with peptic ulcer disease and gastric cancer, ${ }^{12-15}$ but other studies have produced conflicting results. ${ }^{16}$

Particular strains of $H$ pylori have nonopsonic neutrophil activating capacity, and it was shown that such strains are more often isolated from individuals with peptic ulcer disease than from those with chronic gastritis only. ${ }^{17}$ Our earlier studies showed this association was independent of the production of vacuolating cytotoxin. ${ }^{18}$ In our present study, we have examined the incidence and co-expression of cagA and non-opsonic neutrophil activation in wild-type $H$ pylori strains isolated from patients with peptic ulcer disease and chronic gastritis only.

Materials and methods

HELICOBACTER PYLORI STRAINS AND PATIENTS A total of 53 wild-type $H$ pylori strains were included in our study. They were all isolated from antral biopsies taken from 53 individual patients referred for upper gastrointestinal endoscopy at the division of gastroenterology, department of internal medicine, Örebro Medical Centre Hospital, Örebro, Sweden. 
Table 1 Oligonucleotide primers for cagA and ure A PCR

\begin{tabular}{lllll}
\hline Gene & $\begin{array}{l}\text { Accession } \\
\text { number }\end{array}$ & Primer & Position & $\begin{array}{l}\text { Expected } \\
\text { product size }\end{array}$ \\
\hline $\begin{array}{l}\text { cagA } A \\
\text { Anse }\end{array}$ & X 70039 & GATAACGCTGTCGCTTCATACG & $631-652$ & 409 \\
$\begin{array}{l}\text { ure } A \\
\begin{array}{l}\text { Sense } \\
\text { Antisense }\end{array}\end{array}$ & M 60398 & CTGCAAAAGATTGTTTGCAGA & 1039-1018 & \\
\hline
\end{tabular}

Forty nine of the strains had been used in a previous study. ${ }^{17}$ None of the patients had previously received eradication treatment for $H$ pylori infection, and patients on nonsteroidal anti-inflammatory drugs (NSAIDs) were excluded. Histologically, all patients had chronic antral gastritis. Endoscopically, 24 patients had peptic ulcer disease; 10 patients had a duodenal ulcer, one of whom also had a gastric ulcer; seven patients had a prepyloric ulcer; five patients had a gastric ulcer; two patients had a pyloric ulcer, one of whom also had a gastric ulcer.

All the strains showed typical colony morphology, were oxidase, catalase and urease positive, and identified as typical curved rods by Gram stain. For the in vitro experiments, the strains were grown on brain heart infusion agar with $10 \%$ horse blood, without antibiotics, in a microaerophilic atmosphere for two or three days at $37^{\circ} \mathrm{C}$. The individual strains were stored in preservation medium at $-70^{\circ} \mathrm{C}$, and subculturing was kept at a minimum.

\section{NEUTROPHILS}

Heparinised blood from healthy blood donors was used to prepare neutrophils by FicollHypaque (Pharmacia and Upjohn, Uppsala, Sweden) centrifugation in accordance with the method of Böyum, ${ }^{19}$ slightly modified as described previously. ${ }^{20}$ For each series of experiments, neutrophils were prepared and pooled from three blood donors of the same blood group $\left(\mathrm{A} \mathrm{Rh}^{+}\right.$or $\left.\mathrm{O} \mathrm{Rh}^{+}\right)$. Neutrophils were suspended in $0.01 \mathrm{M}$ phosphate buffered $0.15 \mathrm{M}$ saline (PBS) supplemented with $\mathrm{MgCl}_{2}, \mathrm{CaCl}_{2}$, glucose, and gelatin (PBS-GG) as described previously. ${ }^{20}$ The purity and viability of the neutrophils exceeded $95 \%$.

\section{CHEMILUMINESCENCE}

Luminol enhanced chemiluminescence was used as described previously to measure the oxidative burst of neutrophils induced by nonopsonised $H$ pylori organisms. ${ }^{17}$ Briefly, $300 \mu \mathrm{l}$ of PBS-GG, $100 \mu$ of neutrophils $\left(5 \times 10^{6} / \mathrm{ml}\right)$, $50 \mu \mathrm{l}$ of non-opsonised $H$ pylori organisms $\left(5 \times 10^{8} / \mathrm{ml}\right)$, and $50 \mu \mathrm{l}$ of $10^{-5} \mathrm{M}$ luminol (Sigma, St Louis, Missouri, USA) were added to each test tube (LKB, Bromma, Sweden). The measurements with a luminometer (LKB Wallac 1251; LKB, Turku, Finland) were always started within one minute after the bacterial suspension had been added. The assays were performed at $37^{\circ} \mathrm{C}$, and chemiluminescence from each sample was measured at 60-90 second intervals during a period of 30 minutes. The $H$ pylori strains 11637 and C-7050 were used as positive and negative controls, respectively, in each run. ${ }^{17} \mathrm{~A}$ maxi- mum peak response of at least $20 \%$ or more of the reference strain 11637 was regarded as positive.

DNA PREPARATION AND POLYMERASE CHAIN

REACTION (PCR) DETECTION OF cagA

Bacterial colonies from each subject were harvested into PBS, pelleted by centrifugation, and stored at $-70^{\circ} \mathrm{C}$ until assayed. DNA was extracted from the bacterial pellets using phenol/chloroform and precipitated. The presence of cagA was determined by PCR using cagA specific primers (table 1), as described previously. ${ }^{21}$ PCR amplification of ureA was used as a positive control. In each PCR assay, DNA extracted from the cagA positive strain NCTC 11637 and the cagA negative G50 strain $^{7}$ was used as positive and negative controls, respectively. Strains were considered cagA positive when the product of expected size was observed.

\section{STATISTICS}

Fischer's exact test was used for the statistical calculations.

\section{Results}

Tables 2 and 3 show the presence of the cagA gene and non-opsonic neutrophil activation in the $53 \mathrm{H}$ pylori strains, individually and combined, in the 24 patients with peptic ulcer disease and the 29 non-ulcer patients with chronic gastritis only.

The cagA gene was present in 39 of 53 $(73.6 \%)$ strains, 20 of which $(83.3 \%)$ were from patients with peptic ulcer disease, and 19 $(65.5 \%)$ from patients with chronic gastritis only. The corresponding figures for cagA negative strains were four $(16.7 \%)$ and $10(34.5 \%)$, respectively (table 2 ). The difference between the patient groups was not significant $(\mathrm{p}=0.212)$.

Non-opsonic neutrophil activation capacity was found in 29 of $53(54.7 \%)$ strains, 16 of which $(66.7 \%)$ were from patients with peptic ulcer disease, and $13(44.8 \%)$ from patients with chronic gastritis alone. The corresponding

Table 2 Expression of cagA gene and non-opsonic neutrophil activation capacity (NAC) in Helicobacter pylori strains from patients with peptic ulcer disease (PUD) or chronic gastritis (CG)

\begin{tabular}{llrll}
\hline \multirow{5}{*}{ H pylori markers } & & Patients \\
\cline { 2 - 5 } & & PUD & CG & Total \\
\hline \multirow{2}{*}{ cagA gene } & + & 20 & 19 & 39 \\
\multirow{2}{*}{ NAC } & - & 4 & 10 & 14 \\
& + & 16 & 13 & 29 \\
& - & 8 & 16 & 24 \\
\hline
\end{tabular}

Table 3 Expression of cagA gene and non-opsonic neutrophil activation capacity (NAC), individually and combined, in 53 wild-type Helicobacter pylori strains from patients with peptic ulcer disease (PUD) or chronic gastritis (CG)

\begin{tabular}{llrlll}
\hline \multicolumn{3}{c}{ Expression } & & & Total \\
\hline cagA gene & + & + & - & - & \\
NAC & + & - & + & - & \\
PUD & 14 & 6 & 2 & 2 & 24 \\
CG & 9 & 10 & 4 & 6 & 29 \\
Total & 23 & 16 & 6 & 8 & 53 \\
\hline
\end{tabular}


figures for strains without non-opsonic neutrophil activation capacity were eight $(33.3 \%)$ and $16(55.2 \%)$, respectively (table 2$)$. The difference between the patient groups was not significant $(p=0.166)$.

Non-opsonic neutrophil activation was found more frequently in $\operatorname{cagA}^{+}$than cag $\mathrm{A}^{-}$ strains $(59 \% v 42.9 \%)$. Whereas four of the 14 cagA $^{-}$strains and eight of the 24 non-opsonic neutrophil activation negative strains were from patients with peptic ulcer disease, only two of $24(8.3 \%)$ peptic ulcer disease strains expressed neither cagA nor non-opsonic neutrophil activation (tables 2 and 3). The cagA gene and non-opsonic neutrophil activation were co-expressed in 14 of 24 (58.3\%) strains from patients with peptic ulcer disease, and in nine of 29 (31\%) strains from individuals with chronic gastritis. Only one marker-that is, either cagA or non-opsonic neutrophil activation capacity - or none, was expressed in 10 $(41.7 \%)$ strains from patients with peptic ulcer disease, and in 20 of 29 (69\%) strains from individuals with chronic gastritis only. This gives a $p$ value of 0.056 between the two patient groups (Fischer's exact test).

\section{Discussion}

Neutrophils are important cells in the first line of defence against invading microorganisms in general, and pathogenic bacteria in particular. When stimulated to phagocytose they produce an array of reactive oxygen metabolites and release highly biologically active enzymes and other factors, which can be detrimental not only to invading microbes but also to cells and tissues of the host. ${ }^{22}$ Helicobacter pylori strains with the cag pathogenicity island are associated with an enhanced neutrophil response in vivo, ${ }^{12}{ }^{23}$ probably because of their ability to induce IL-8 production in gastric epithelial cells. ${ }^{7-11}$ Therefore, we hypothesised that the co-expression of cagA and non-opsonic neutrophil activation capacity in wild-type clinical $H$ pylori isolates might be related to the mucosal damage associated with $H$ pylori infection. Our findings support this view, and co-expression of cagA and non-opsonic neutrophil activation enhanced the prediction of peptic ulcer disease as compared with chronic gastritis only.

The mosaicism of the cagA genotype and non-opsonic neutrophil activation capacity among the clinical isolates was obvious. One or both of these factors occurred in 45 of 53 $(84.9 \%)$ strains, and they were more frequently found in patients with peptic ulcer disease than in individuals with chronic gastritis only $(91.7 \% \vee 79.3 \%)$. The lack of a significant association between non-opsonic neutrophil activation and peptic ulcer disease is in contrast to one previous study. ${ }^{17}$ However, only 49 of the 55 strains used in our previous study were included in our present study. Nonetheless, non-opsonic neutrophil activation was more frequent in patients with peptic ulcer disease than in individuals with chronic gastritis $(66.7 \%$ v $44.8 \%)$.

Helicobacter pylori are broadly divided into type I and type II strains, the former character- ised by the presence of CagA, a marker of the cag pathogenicity island, ${ }^{10}{ }^{11}$ and the production of vacuolating cytotoxin, VacA. ${ }^{24}$ In between the two extremes of type I and type II, there are a number of subpopulations of intermediate strains. $^{24}$ In studies to predict the clinical outcome of $H$ pylori infection, considerable attention has been paid to vacA and cagA genotypes. ${ }^{15162125}$ Even though many studies from Europe and the USA show particular vacA genotypes to be significantly more frequent in patients with peptic ulcer disease than in individuals with non-ulcer dyspepsia, ${ }^{15} 26$ there are studies, particularly from countries in Asia, with conflicting results. ${ }^{27} 28$ In earlier studies, we found that all the strains with vacuolating cytotoxin activity were positive either for non-opsonic neutrophil activation or for cagA, or both (D Danielsson et al. Presented at the North American Helicobacter pylori meeting, Foundation for Gastrointestinal Microbial Pathogens; Phoenix Arizona, February 27-28, 1998). ${ }^{18}$ In fact, more than $80 \%$ of cytotoxin producing strains co-expressed the cagA gene and non-opsonic neutrophil activation. Even though CagA, nonopsonic neutrophil activation, and the VacA cytotoxin may occur independently, it is obvious that the concomitant occurrence of two or all three markers will enhance the prediction of clinical outcome. Whereas the genetic loci for cagA and vacA are known, the gene encoding non-opsonic neutrophil activation capacity remains to be determined.

In summary, co-expression in H pylori strains of non-opsonic neutrophil activation and the cag pathogenicity island will enhance gastric mucosal inflammation, and together with the vacuolating cytotoxin could be considered as virulence factors that can be used to predict clinical outcome.

We thank the Northern and Yorkshire Regional Health Authority, European Commission, Yorkshire Cancer Research, and the Research Foundation of Örebro Medical Centre Hospital for financial support.

1 Warren JR, Marshall BJ. Unidentified curved bacilli on gasric epithelium in active chronic gastritis. Lancet 1983;1:1273-5

2 Sipponen P, Hyvärinen H. Role of Helicobacter pylori in the pathogenesis of gastritis, peptic ulcer and gastric cancer. Scand $\mathcal{F}$ Gastroenterol 1993;196(suppl):3-6.

3 Parsonnet JGD, Friedman DP, Vandersteen Y, et al. Helicobacter pylori infection and the risk of gastric carcinoma. $N$ Engl F Med 1991;325:1127-31.

4 Labigne A, Cussac V, Courcoux P. Shuttle cloning and nucleotide sequences of Helicobacter pylori genes responsible for urease activity. F Bacteriol 1991;173:1920-31.

5 Leyning H, Suerbaum S, Geis G, et al. Cloning and genetic characterization of a Helicobacter pylori flagellar gene. Mol

6 Dixon MF, Genta RM, Yardley JH, et al. Classification and Dixon MF, Genta RM, Yardley JH, et al. Classification
grading of gastritis. Am $\mathcal{F}$ Surg Pathol 1996;20:1161-81.

7 Crabtree JE, Covacci A, Farmery SM, et al. Helicobacter pylori induced interleukin-8 expression in gastric epithelial cells is associated with CagA positive phenotypes. $\mathcal{F}$ Clin Pathol 1995;48:41-5.

8 Sharma SA, Tummuru MKR, Miller GG, et al. Interleukin-8 response of gastric epithelial cell lines to Helicobacter pylori stimulation in vitro. Infect Immun 1995; 63:1681-87

9 Crabtree JE. Role of cytokines in pathogenesis of Helicobacter pylori-induced mucosal damage. Dig Dis $\mathrm{Sci}$ 1998;43 (suppl):46S-55S.

10 Censini S, Lange C, Xiang Z, et al. cag, a pathogenicity island of Helicobacter pylori, encodes type I-specific and disease-associated virulence factors. Proc Natl Acad Sci U S A 1996;93:14648-53.

11 Akopyantz NS, Clifton SW, Kersulyte D, et al. Analyses of cag pathogenicity island of Helicobacter pylori. Mol Microbiol 1998;28:37-53. 
12 Crabtree JE, Taylor JD, Wyatt JI, et al. Mucosal IgA recognition of Helicobacter pylori $120 \mathrm{kDa}$ protein, peptic

13 Covacci A, Censini S, Buguoli M, et al. Molecular Covacci A, Censini S, Buguoli $\mathrm{M}$, et al. Molecular
characterization of the $128-\mathrm{kDa}$ immunodominant antigen of Helicobacter pylori associated with cytotoxicity and duodenal ulcer. Proc Natl Acad Sci U S A 1993;90:5791-5.

14 Blaser MJ, Pérez-Pérez GI, Kleanthous $\mathrm{H}$, et al. Infections of strains possessing cagA is associated with an increased risk of developing adenocarcinoma of the stomach. Cancer Res 1995;55:2111-15.

15 Atherton JC, Peek RM, Tham KT, et al. Clinical and pathological importance of heterogeneity in vacA, the vacuolating cytotoxin gene of Helicobacter pylori. Gastroenterology 1997;112:92-9.

16 Pan ZI, van der Hulst RM, Feller M, et al. Equally high prevalence of infection with cagA positive Helicobacter pylori in Chinese patients with peptic ulcer disease and chronic associated dyspepsia. 7 Clin Microbiol 1997;35:1344-7.

17 Rautelin H, Blomberg B, Fredlund H, et al. Incidence of Helicobacter pylori strains activating neutrophils in patients with peptic ulcer disease. Gut 1993;34:599-603.

18 Rautelin H, Blomberg B, Järnerot G, et al. Nonopsonic activation of neutrophils and cytotoxin production by Helicobacter pylori: ulcerogenic markers. Scand $\mathcal{F}$ Gastroenterol 1994;29:128-32.

19 Böyum A. Separation of blood leucocytes, granulocytes and lymphocytes. Tissue Antigens 1974;4:269-74.

20 Fredlund H, Olcén P, Danielsson D. A reference procedure to study chemiluminescence induced in polymorphonuclear leucocytes by Neisseria meningitidis. APMIS 1988; 96:941-9.
21 Peek RM, Miller GG, Tham KK, et al. Detection of Helicobacter pylori gene expression in human gastric mucosa. $\mathcal{F}$ Clin Microbiol 1995;33:28-32.

22 Babior BM. Oxygen dependent microbial killing by phagocytes. N Engl f Med 1978;298:659-68.

23 Shimoyama T, Everett SM, Dixon MF, et al. Chemokine mRNA expression in gastric mucosa is associated with Helicobacter pylori cagA positivity and severity of gastritis. f Clin Pathol 1998;51:765-70.

24 Xiang Z, Censini S, Bayeli PF, et al. Analysis of expression of $\mathrm{CagA}$ and VacA virulence factors in 43 strains of Helicobacter pylori reveals that clinical isolates can be divided into two major types and that CagA is not necessary for expression of the vacuolating cytotoxin. Infect Immun 1995;63:94-8.

25 van Doorn LJ, Figueiredo C, Rossan R, et al. Typing of Helicobacter pylori vacA gene and detection of cagA gene by PCR and reverse hybridization. I Clin Microbiol 1998;36:1271-6.

26 Strobel S, Bereswill S, Balig P, et al. Identification and analysis of a new vacA genotype variant of Helicobacter pylori in different patient groups in Germany. F Clin Microbiol 1998;36:1285-9.

27 Ito Y, Azuma T, Ito S, et al. Analysis and typing of the vacA gene from cagA positive strains of Helicobacter pylori isolated in Japan. $\mathcal{F}$ Clin Microbiol 1997;35:1710-14.

28 Pan ZJ, Berg DE, van der Hulst RW, et al. Prevalence of vacuolating cytotoxin production and distribution of distinct vacA alleles in Helicobacter pylori from China. $\mathcal{F}$ Infect Dis 1998;188:220-6. 